\title{
Abnormal phosphorylation of Tie2/Akt/ eNOS signaling pathway and decreased number or function of circulating endothelial progenitor cells in prehypertensive premenopausal women with diabetes mellitus
}

\author{
Haitao Zeng ${ }^{1 \dagger}$, Yanping Jiang ${ }^{2 \dagger}$, Hailin Tang $^{3}$, Zi Ren $^{1}$, Gaofeng Zeng ${ }^{2}$ and Zhen Yang ${ }^{4^{*}}$
}

\begin{abstract}
Backgrounds: The number and activity of circulating endothelial progenitor cells (EPCs) in prehypertension is preserved in premenopausal women. However, whether this favorable effect still exists in prehypertensive premenopausal women with diabetes is not clear.

Methods: This study compared the number and functional activity of circulating EPCs in normotensive or prehypertensive premenopausal women without diabetes mellitus and normotensive or prehypertensive premenopausal women with diabetes mellitus, evaluated the vascular endothelial function in each groups, and investigated the possible underlying mechanism.

Results: We found that compared with normotensive premenopausal women, the number and function of circulating EPCs, as well as endothelial function evaluated by flow-mediated dilatation (FMD) in prehypertensive premenopausal women were preserved. In parallel, the Tie2/Akt/eNOS signaling pathway and the plasma NO level or NO secretion of circulating EPCs in prehypertensive premenopausal women was also retained. However, in presence of normotension or prehypertension with diabetes mellitus, the number or function of circulating EPCS and FMD in premenopausal women decreased. Similarly, the phosphorylation of Tie2/Akt/eNOS signaling pathway and the plasma NO level or NO secretion of circulating EPCs was reduced in prehypertension premenopausal with diabetes mellitus.

Conclusion: The present findings firstly demonstrate that the unfavorable effects of diabetes mellitus on number and activity of circulating EPCs in prehypertension premenopausal women, which is at least partially related to the abnormal phosphorylation of Tie2/Akt/eNOS signaling pathway and subsequently reduced nitric oxide bioavailability. The Tie2/Akt/eNOS signaling pathway may be a potential target of vascular protection in prehypertensive premenopausal women with diabetes mellitus.
\end{abstract}

Keywords: Prehypertension, Diabetes mellitus, Endothelial progenitor cells, Endothelial function, Tie2 signaling pathway

\footnotetext{
*Correspondence: yangzhen10710710@163.com

${ }^{\dagger}$ Equal contributors

${ }^{4}$ Department of Hypertension \& Vascular Disease, The First Affiliated Hospital,

Sun Yat-Sen University, Guangzhou 510080, People's Republic of China

Full list of author information is available at the end of the article
} 


\section{Background}

Prehypertension is an intermediate state between normotension and hypertension, which is associated with increased cardiovascular risks [1-6]. Endothelial dysfunction, accompanied by prehypertension, plays a crucial role in initiation and progression of atherosclerotic vascular disease and subsequent clinical consequences [7-9]. Increasing evidence suggests that circulating endothelial progenitor cells (EPCs) are thought to be a subset of cells derived from the bone marrow that plays a pivotal role in accelerating reendothelialization, repairing endothelial injury and improving endothelial function [10-13]. However, in presence of risk factors for cardiovascular disease such as prehypertension, obesity and smoke, the number and activity of circulating EPC decreased, which may contribute to the development of endothelial injury [14-16].

It is well known that diabetes mellitus (DM) is a complex metabolic disorder characterized by increased morbidity and mortality rates. Compared with nondiabetic controls, patients with DM have a high risk of developing cardiovascular complications [17, 18], which correlated with endothelial injury and dysfunction [19-22]. In presence of diabetes, the number and activity of circulating EPCs, as well as flow-mediated dilatation (FMD) were impaired [23-25]. Meanwhile, the number and activity of circulating EPCs is related to endothelial function as evaluated by measurement of FMD [26, 27]. These results implies that the attenuated endothelial repair capacity may be lead to diabetes-related vascular injury.

It has proved that the occurrence of cardiovascular risk is lower in premenopausal women than postmenopausal women and age-matched men $[28,29]$. The increased cardiovascular diseases risks in postmenopausal women may be partly associated with endothelial injury and dysfunction [30]. Our previous studies showed that the number and activity of circulating EPCs in prehypertensive premenopausal women were preserved, indicating the retained endothelial repair capacity may contribute to vascular protection concomitant with prehypertensive premenopausal women [31]. However, whether the beneficial effect still exists in prehypertensive premenopausal women with diabetes is still unclear. According to the previous studies revealing the unfavorable effect of DM on circulating EPCs [23-25], we hypothesized that the number and activity of circulating EPCs might be impaired in premenopausal prehypertensive women with diabetes. In addition, nitric oxide (NO), vascular endothelial growth factors (VEGF), and granulocyte macrophage colony- stimulating factor (GMCSF) regulate the number and function of circulating EPCs [32-35]. EPC-mediated endothelial repair capacity is associated with NO secretion by EPCs [36]. Tie2/
PI3K/Akt signaling pathway is one major upstream effectors of eNOS. Our study and other investigations indicated that the Tie2/Akt/eNOS signaling play an important role in regulating the function of circulating EPCs [37-40]. Based on the prior reports, we further assumed that the changes of EPCs in the three groups might be related to the alteration of NO, VEGF, GMCSF level in plasma or secretion by circulating EPCs, and downregulation of Tie2/Akt/eNOS signaling pathway in circulating EPCs might be also responsible for decreased EPCs functional activity in premenopausal prehypertensive women with diabetes. Hence, we observed normotensive or prehypertensive premenopausal women without diabetes mellitus and normotensive or prehypertensive premenopausal women with diabetes mellitus, evaluated the levels of NO、 VEGF and GMCSF in plasma or culture medium, and investigated the expression of tie2/Akt/eNOS signaling pathway in each groups. This study may provide useful information on our understanding of the novel mechanism underlying the alteration of endothelial repair capacity in prehypertensive premenopausal women with diabetes mellitus.

\section{Methods}

\section{Characteristics of subjects}

Twenty normotensive premenopausal women, twenty prehypertensive premenopausal women, twenty normotensive premenopausal women with type 2 diabetes mellitus, and 20 prehypertensive premenopausal women with type 2 diabetes mellitus were studied. The enrolled subjects had no known cardiovascular disease or ongoing drug treatments (such as antiplatelet, anti-inflammatory or hypolipidemic agents). The normotensive premenopausal women had no cardiovascular risk factors, a systolic blood pressure $<120 \mathrm{mmHg}$, and a diastolic blood pressure $<80 \mathrm{mmHg}$. The prehypertensive women were diagnosed as systolic blood pressure between 120 and $139 \mathrm{mmHg}$ or diastolic blood pressure between 80 and $89 \mathrm{mmHg}$ according to the Eight Joint National Committee (JNC 8) guidelines [41]. Prehypertensive women with type 2 diabetes mellitus was newly diagnosed without any drug treatments according to the guidelines in the Expert Committee Report of the American Diabetes Association [42]. The subjects with smokers, malignant disease, infection, or inflammatory disorders were excluded as all these conditions may influence the number or activity of EPC. The subjects with breastfeeding or pregnant women and those with previous hysterectomy or irregular menstrual cycles were also excluded. The protocol of this study was approved by the Ethics Committee of the sixth affiliated hospital of Sun Yat-Sen University, and written informed consent for participation in the study was obtained from participants. The main characteristics of the study population are shown in Table 1. 
Table 1 Clinical and biochemical characteristics

\begin{tabular}{|c|c|c|c|c|}
\hline \multirow[t]{2}{*}{ Characteristics } & Normotensive women & Prehypertensive women & $\begin{array}{l}\text { Normotensive women } \\
\text { with DM }\end{array}$ & $\begin{array}{l}\text { Prehypertensive women } \\
\text { with DM }\end{array}$ \\
\hline & $(n=20)$ & $(n=20)$ & $(n=20)$ & $(n=20)$ \\
\hline Age (years) & $42.7 \pm 5.8$ & $44.9 \pm 4.0$ & $45.2 \pm 6.6$ & $45.4 \pm 5.1$ \\
\hline Height (cm) & $162.3 \pm 5.7$ & $160.5 \pm 5.9$ & $161.9 \pm 6.1$ & $161.1 \pm 5.2$ \\
\hline Weight (Kg) & $58.7 \pm 5.7$ & $59.5 \pm 5.7$ & $62.1 \pm 4.8$ & $64.1 \pm 4.4$ \\
\hline $\mathrm{BMI}\left(\mathrm{kg} / \mathrm{cm}^{2}\right)$ & $23.5 \pm 2.7$ & $22.9 \pm 2.1$ & $24.0 \pm 2.1$ & $23.8 \pm 1.5$ \\
\hline Systolic blood pressure (mmHg) & $108.8 \pm 6.5$ & $130.4 \pm 5.5^{\mathrm{a}}$ & $111.0 \pm 6.0$ & $131.3 \pm 4.9^{a}$ \\
\hline Diastolic blood pressure $(\mathrm{mmHg})$ & $68.5 \pm 5.0$ & $80.3 \pm 4.4^{\mathrm{a}}$ & $70.9 \pm 4.8$ & $80.9 \pm 5.4^{\mathrm{a}}$ \\
\hline Heart rate (beats/min) & $72.2 \pm 7.9$ & $72.8 \pm 7.4$ & $73.7 \pm 10.2$ & $75.0 \pm 7.7$ \\
\hline AST (mmol/L) & $24.3 \pm 5.8$ & $26.9 \pm 8.1$ & $27.7 \pm 6.0$ & $25.7 \pm 6.5$ \\
\hline $\mathrm{ALT}(\mathrm{mmol} / \mathrm{L})$ & $22.9 \pm 5.2$ & $24.5 \pm 5.1$ & $24.8 \pm 6.1$ & $21.7 \pm 5.7$ \\
\hline BUN (mmol/L) & $5.7 \pm 0.8$ & $5.5 \pm 1.2$ & $5.9 \pm 1.3$ & $5.4 \pm 1.1$ \\
\hline $\mathrm{Cr}(\mathrm{mmol} / \mathrm{L})$ & $72.2 \pm 14.8$ & $66.4 \pm 16.4$ & $73.1 \pm 15.2$ & $65.2 \pm 18.0$ \\
\hline LDL (mmol/L) & $2.98 \pm 0.33$ & $2.88 \pm 0.55$ & $3.10 \pm 0.37$ & $3.09 \pm 0.36$ \\
\hline TC (mmol/L) & $4.93 \pm 0.44$ & $4.92 \pm 0.65$ & $5.11 \pm 0.39$ & $5.08 \pm 0.42$ \\
\hline $\mathrm{HDL}(\mathrm{mmol} / \mathrm{L})$ & $1.37 \pm 0.24$ & $1.40 \pm 0.21$ & $1.31 \pm 0.19$ & $1.34 \pm 0.16$ \\
\hline TG (mmol/L) & $1.44 \pm 0.19$ & $1.39 \pm 0.17$ & $1.50 \pm 0.21$ & $1.46 \pm 0.12$ \\
\hline FPG (mmol/L) & $4.71 \pm 0.67$ & $4.51 \pm 0.61$ & $8.91 \pm 1.16^{b}$ & $8.73 \pm 1.08^{b}$ \\
\hline 2hPG(mmol/L) & $6.25 \pm 0.66$ & $6.17 \pm 0.67$ & $10.87 \pm 1.72^{b}$ & $10.31 \pm 1.61^{b}$ \\
\hline $\mathrm{HbA}_{1} \mathrm{C}(\%)$ & $5.31 \pm 0.58$ & $5.18 \pm 0.63$ & $8.49 \pm 1.47^{b}$ & $8.15 \pm 1.52^{b}$ \\
\hline $\operatorname{hrCRP}(\mathrm{mmol} / \mathrm{L})$ & $0.961 \pm 0.509$ & $1.130 \pm 0.615$ & $1.953 \pm 0.852^{b}$ & $1.828 \pm 0.882^{b}$ \\
\hline FMD(\%) & $10.29 \pm 1.16$ & $9.79 \pm 1.22$ & $5.87 \pm 5.49^{b}$ & $5.49 \pm 0.129^{b}$ \\
\hline GMD(\%) & $22.49 \pm 2.12$ & $21.89 \pm 2.45$ & $21.05 \pm 2.47$ & $21.37 \pm 2.68$ \\
\hline
\end{tabular}

Abbreviation: $B M I$ body mass index, $L D L$ low-density lipoprotein, $T C$ total cholesterol, $H D L$ high density lipoprotein, $T G$ triglyeride, $F P G$ fasting plasma glucose, $2 h P G$ 2-h plasma glucose, $\mathrm{HbA}_{1} \mathrm{C}$ glycosylated hemoglobin, hrCRP hyper-sensitive C-reactive protein, GMD glyceryl trinitrate-mediated dilation, FMD flow-mediated brachial artery dilatation

Notes: Data are given as mean $\pm \mathrm{SD}$. ${ }^{\mathrm{a}} \mathrm{vs}$ normotension; ${ }^{\mathrm{b}} \mathrm{vs}$ without DM

All peripheral venous blood samples used for EPCs isolation and routine blood and biochemistry tests including serum total cholesterol, triglycerides, highdensity lipoprotein cholesterol, LDL-cholesterol, fasting blood glucose (FBG) and high-sensitivity CRP were taken from the three groups in the morning after overnight fasting. All subjects received checks, menstrual periods of the menstrual cycle (day 2 to day 5 after the first day of menstrual bleeding).

\section{Evaluation of number of circulating EPCs by flow cytometry analysis and cell culture assay}

Detection of EPCs was performed as our previous studies and other investigation described $[40,43]$. The count of circulating EPCs was evaluated by the ratio of CD34 + KDR+ cells per 100 peripheral blood mononuclear cells (PBMNCs). The circulating EPCs were isolated, cultured and quantified using DiI-acLDL uptake and FITC-labled Ulex europeus agglutin (lectin) staining as our previous described report [40]. The cultured EPC number was evaluated by DiI-acLDL/lectin doublepositive cells $/ \times 200$, and counted manually by two independent observers blinded to the study.

\section{Migration and Proliferation assay of circulating EPCs}

EPC migration and proliferation assay was determined as our previous studies reported [40, 43]. EPCs were harvested by centrifugation, resuspended in $500 \mu \mathrm{l}$ EBM, and counted. Then, $2 \times 10^{4}$ EPCs were placed in the upper chamber of a modified Boyden chamber. The chamber was placed in a 24-well culture dish containing EBM and human recombinant VEGF $(50 \mathrm{ng} / \mathrm{mL})$. After incubation at $37^{\circ} \mathrm{C}$ for $24 \mathrm{~h}$, the lower side of the filter was washed with PBS and fixed with $2 \%$ paraformaldeyde. For quantification, cell nuclei were stained with DAPI. Cells migrating into the lower chamber were counted manually in 3 random microscopic fields.

EPC proliferation was performed as following. After being cultured for 7 days, EPCs were digested with $0.25 \%$ trypsin and then cultured in serum-free medium in 96-well culture plate $(200 \mu \mathrm{L} /$ well $)$. After being cultured for $24 \mathrm{~h}$, EPCs were supplemen-ted with $10 \mu \mathrm{l}$ 
MTT (5 g/L, Fluka Co. Product) and incubated for another $4 \mathrm{~h}$. Then the supernatant was discarded by aspiration and the EPC preparation was shaked with $200 \mu \mathrm{L}$ dimethyl sulfoxide (DMSO) for $10 \mathrm{~min}$, before the OD value was measured at $490 \mathrm{~nm}$.

\section{Measurement of NO、VEGF and GM-CSF levels in plasma and secretion by EPCs}

Plasma was assayed for NO、VEGF and GM-CSF levels. Nitrite, the stable metabolite of nitric oxide, was estimated by using Greiss method as our previous studies reported [32]. The formation of nitrite $\left(\mathrm{NO}_{2}^{-}\right)$and nitrate $\left(\mathrm{NO}_{3}^{-}\right)$was detected in cell culture supernatants. This assay determined the total NO based on the enzymatic conversion of $\mathrm{NO}_{3}^{-}$to $\mathrm{NO}_{2}^{-}$by nitrate reductase (Sigma), and detection of nitrite as an azo dye product of the Greiss reaction. The results are presented as $\mu$ mol $\mathrm{NO}_{\mathrm{x}}$ of $\mathrm{NO}_{3}{ }^{-} / \mathrm{NO}_{2}^{-}$per liter of medium. Plasma levels of VEGF and GM-CSF were measured by high-sensitive ELISA assays (R\&D Systems, Wiesbaden, Germany) according to our previous studies [32].

The cultured EPCs were switched to the DMEM/20 \%fetal bovine serum (no supplemental growth factors) for $48 \mathrm{~h}$. Then, the conditioned media were assayed for NO、VEGF and GM-CSF as previously described [32].

\section{Flow mediated dilatation}

The measurement of FMD were performed according to the previous reports $[44,45]$. Brachial artery FMD was measured by highresolution ultrasonography using a 5$12 \mathrm{MHz}$ linear transducer on an HDI 5000 system (Washington, USA). The brachial artery was studied 20 to $100 \mathrm{~mm}$ proximal to the antecubital fossa in supine participants after $15 \mathrm{~min}$ rest $[44,45]$. Pressure in an upper-forearm sphygmomanometer cuff was raised to $250 \mathrm{mmHg}$ for $5 \mathrm{~min}$ and FMD calculated as the percentage increase in mean diastolic diameter after reactive hyperaemia 55 to $65 \mathrm{~s}$ after deflation to baseline [44, 45]. After a further $15 \mathrm{~min}, 400 \mu \mathrm{g}$ sublingual glyceryl trinitrate (GTN) was given and diastolic diameter remeasured after $5 \mathrm{~min}$ for measurement of endothelialindependent dilatation $[44,45]$.

\section{Western blot analysis}

EPC proteins were harvested by cell lysis buffer (Cell SignalingTechnology Inc, Danvers, MA, USA). Protein extracts were subjected to SDS-PAGE, transferred to polyvinylidene fluoride membranes(Cell Signaling Technology Inc.). The following antibodies were used: rabbit phospho-Tie2, Tie2, phospho-Akt, Akt, phospho-eNOS, eNOS(1:1000; Cell Signaling Technology Inc.) and $\beta$ actin (1:1000; Santa Cruz Technology Inc.). Proteins were visualized with HRP-conjugated anti-rabbit IgG (1:2000; Cell Signaling Technology Inc.) or HRP- conjugated anti-mouse IgG (1:5000; Cell Signaling Technology Inc.), followed by use of the ECL chemiluminescence system (Cell Signaling Technology Inc.). The intensity of immunoreactive bands was analyzed. The results were expressed as the ratio of specific phosphorylated proteins to total proteins for the phosphorylation of Tie2, Akt, and eNOS in human EPCs, and the ratio of total Tie2, Akt, and eNOS proteins to ß-actin for expression of Tie2, Akt, and eNOS in human EPCs. The statistical comparisons for western blot analysis were made relative to normotension.

\section{Statistic analysis}

The statistic software was SPSS V11.0 (SPSS Inc., Chicago, Illinois). All data were expressed as mean \pm SD. Comparisons between the four groups were analyzed by two-factor analysis of variance (status of with or without diabetes mellitus, status of normotension or prehypertension). When indicated by a significant $F$-value, a post hoc test using the Newman-Keuls method identified significant differences among mean values. Comparisons in Tie2/Akt/eNOS signaling pathway between the three groups were analyzed by using the unpaired Student's $t$ test and one-way ANOVA. Univariate correlations were calculated using Pearson's coefficient (r). P-values less than 0.05 were considered statistical significance.

\section{Results}

\section{Clinical characteristics}

As shown in Table 1, the four groups were similar in terms of age and BMI. There were no differences between the levels of triglycerides, cholesterol, LDLcholesterol, high-density lipoprotein cholesterol in the three groups $(P>0.05)$. Compared with normotensive premenopausal women with or without diabetes mellitus, the systolic and diastolic blood pressure in prehypertensive premenopausal women with or without diabetes mellitus was higher $(P<0.05)$. FBG, 2hPG, $\mathrm{HbA} 1 \mathrm{C}$, FMD and hr-CRP in normotensive or prehypertensive women with diabetes mellitus were significantly higher than those in normotensive or prehypertensive women without diabetes mellitus $(P<0.05)$. However, there were no differences in FMD between normotensive and prehypertensive women $(P>0.05)$. The GMD in the four groups was similar $(P>0.05)$.

\section{The number and function of circulating EPCs in the four groups}

As shown in Fig. 1a and b, there was no difference in number of circulating EPCs evaluated by FACS analysis or cell culture assay between normotensive and prehypertensive premenopausal women $(P>0.05)$. However, the number of circulating EPCs was significantly lower in normotensive or prehypertensive premenopausal 

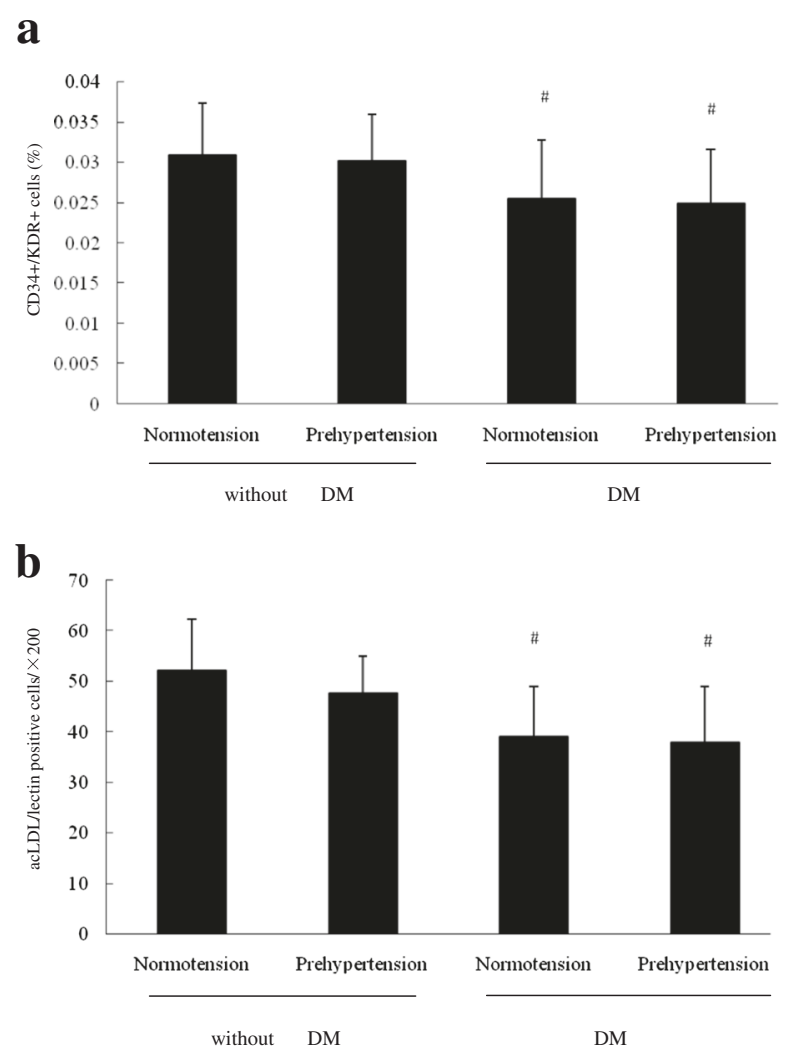

\section{C}

d
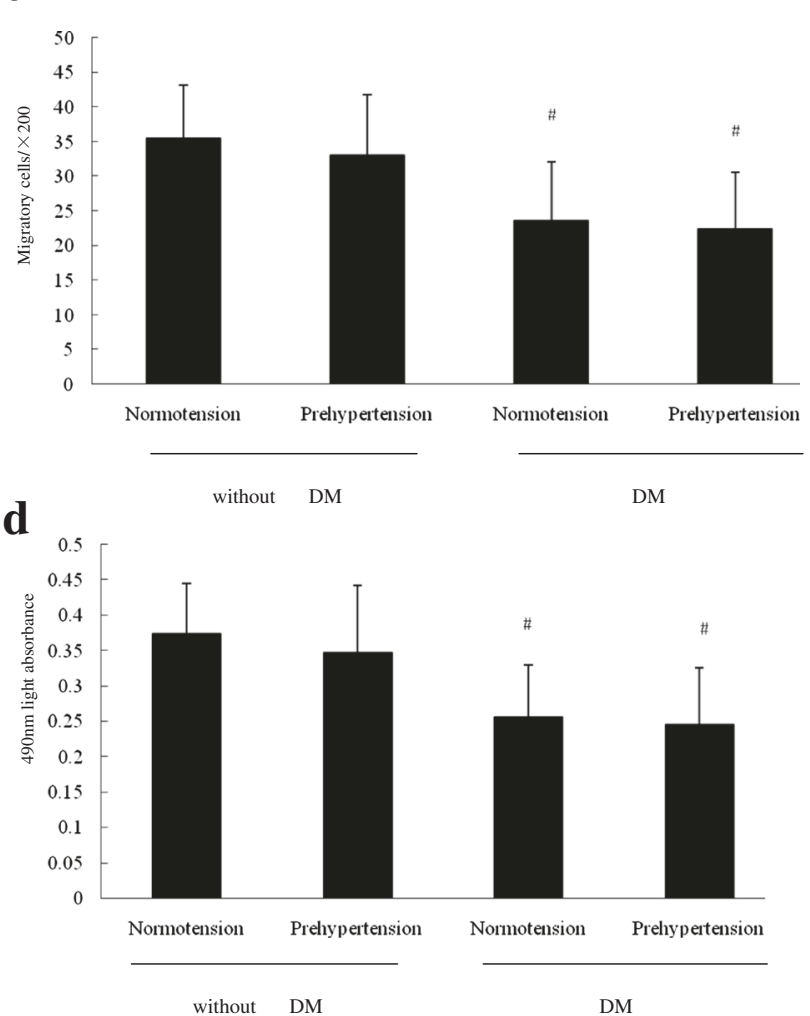

Fig. 1 The number and activity of circulating EPCS in the four groups. Evaluated by a FACS analysis or $\mathbf{b}$ cell culture assay, the number of circulating EPCS in prehypertensive premenopausal women without diabetes mellitus was similar to that in normotensive premenopausal women without diabetes mellitus, but higher than that in normotensive or prehypertensive women with diabetes mellitus. There was no difference in the migratory $\mathbf{c}$ and proliferative $\mathbf{d}$ activities between normotensive and prehypertensive premenopausal women. The migratory $\mathbf{c}$ and proliferative $\mathbf{d}$ activities of cultured EPCs was lower in normotensive or prehypertensive premenopausal women with diabetes mellitus than that in normotensive or prehypertensive premenopausal women without diabetes mellitus. Data are given as mean \pm SD ( ${ }^{*}$ vs normotension; ${ }^{*}$ vs without DM, $n=20$ for each group)

women with diabetes mellitus than that in normotensive or prehypertensive premenopausal women without diabetes $(P<0.05)$. Figure $1 \mathrm{c}$ and $\mathrm{d}$ showed that the migratory or proliferative function of EPCs in normotensive premenopausal women was equal to that in prehypertensive premenopausal women $(P>0.05)$. However, the migratory or proliferative function of EPCs in normotensive or prehypertensive premenopausal women with diabetes were lower than those in normotensive or prehypertensive premenopausal women without diabetes $(P<0.05)$. These results indicated that the preserved number and activity of circulating EPCs in prehypertensive premenopausal women was impaired in presence of diabetes.

Plasma NO、VEGF and GM-CSF levels in the four groups As shown in Fig. 2, the plasma NO levels in normotensive premenopausal women was similar to that in prehypertensive premenopausal women $(P>0.05)$. However, the plasma NO levels in normotensive or prehypertensive premenopausal women with diabetes were significantly lower than those in normotensive or prehypertensive premenopausal women without diabetes $(P<0.05)$. Different from the plasma NO level, there was no significant difference in the plasma VEGF and GM-CSF level among the four groups $(P>0.05)$.

\section{NO、VEGF and GM-CSF secretion by EPCs in the four groups}

Figure 3 showed the NO、VEGF and GM-CSF secretion by EPCs in the four groups. The NO secretion by cultured EPCs in normotensive premenopausal women without diabetes was almost equal to that in prehypertensive premenopausal women without diabetes $(P>0.05)$, but higher than that in normotensive or prehypertensive women with diabetes mellitus $(P<0.05)$. However, no difference was shown among the four groups in term of either VEGF or GM-CSF secretion by cultured EPCs $(P>0.05)$. 

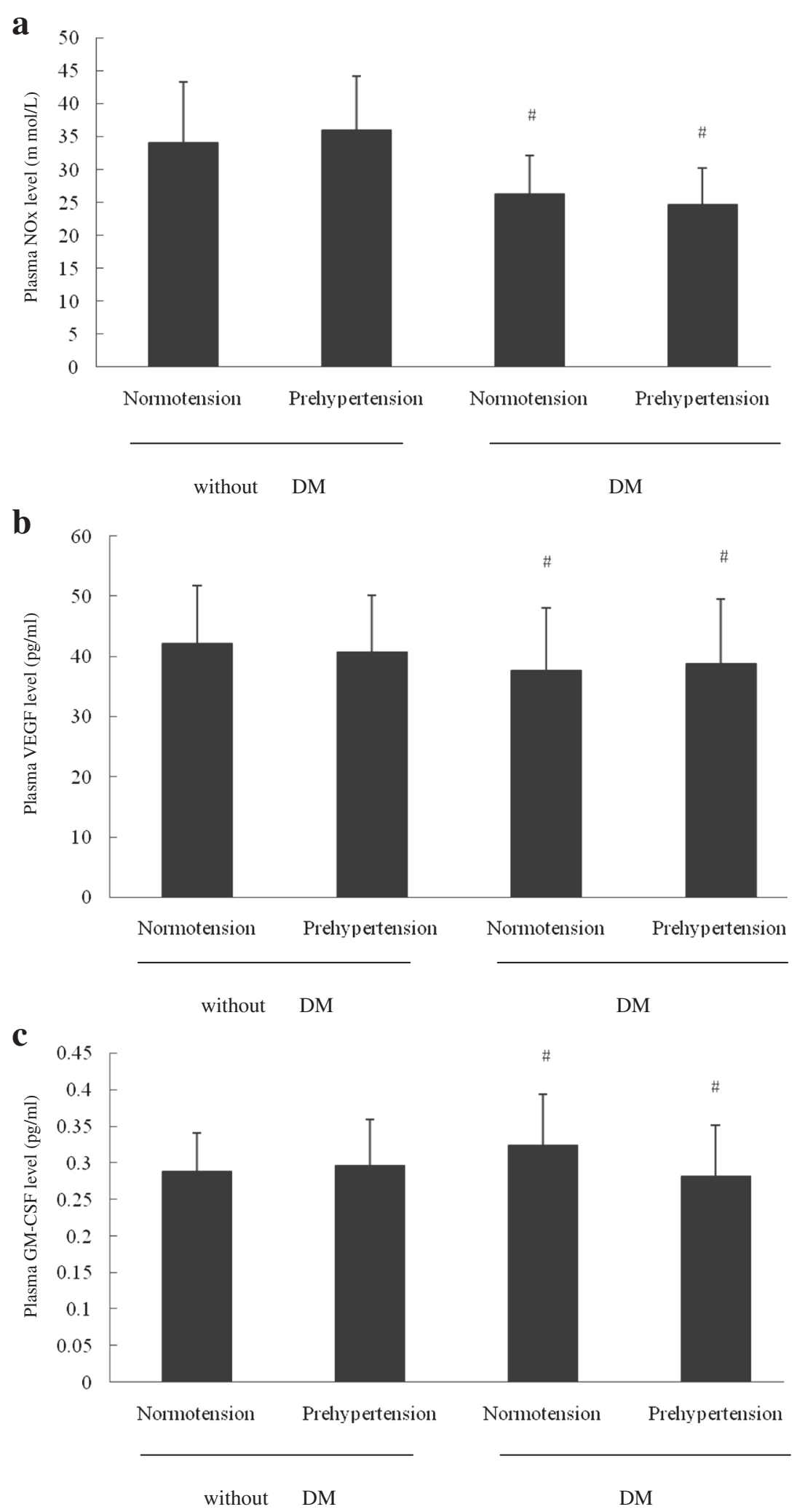

Fig. 2 (See legend on next page.) 
(See figure on previous page.)

Fig. 2 The plasma NO、VEGF and GM-CSF levels in the four groups. a The plasma NO level in normotensive premenopausal women without diabetes mellitus was almost equal to that prehypertensive premenopausal women without diabetes mellitus. Compared with normotensive or prehypertensive premenopausal women without diabetes mellitus, the plasma NO level in normotensive or prehypertensive women with diabetes mellitus decreased. No significant difference was found in plasma VEGF $\mathbf{b}$ or GM-CSF c level among the four groups. Data are given as mean \pm SD ("vs normotension; ${ }^{*}$ vs without $\mathrm{DM}, n=20$ for each group)

\section{Correlation between circulating EPCs or NO level and FMD}

Figure $4 \mathrm{a}$ and $\mathrm{d}$ showed that the correlation between the number or function of circulating EPCs and FMD. There was significant correlation between FMD and the number of circulating EPCs evaluated by flow cytometry analysis $(r=0.41, P<0.05)$ or by cell culture $(r=0.74, P<0.05)$. Similarly, the EPC migration and EPC proliferation significantly correlated with plasma FMD $(r=0.64, P<0.05$, and $r=0.56, P<0.05$, respectively). Figure $4 \mathrm{e}$ and $\mathrm{f}$ showed that the correlation between the plasma NO level and NO secretion by EPCs and FMD. There was obvious correlation between FMD and plasma NO level $(r=0.63, P<0.05)$, and NO secretion by EPCs $(r=0.62, P<0.05)$.

\section{The Tie2/Akt/eNOS signaling pathway of circulating EPCs in the three groups}

To investigate the possible mechanism underlying the deficiency in NO secretion by cultured EPCs in presence of prehypertension with diabetes mellitus, we further evaluated the expression of Tie2/Akt/eNOS signaling pathway of circulating EPCs in the three groups. As shown in Fig. 5, the phosphorylation of tie2, Akt and eNOS of circulating EPCs in prehypertensive premenopausal women and normotensive premenopausal women without diabetes exhibited no significant difference $(P>0.05)$. However, the phosphorylation of tie2, Akt, and eNOS of circulating EPCs in prehypertensive and normotensive premenopausal women without diabetes were higher than that in prehypertensive premenopausal women with diabetes mellitus $(P<0.05)$. In addition, there was no difference in the expression of total tie2, Akt and eNOS of circulating EPCs in the three groups $(P>0.05)$.

\section{Discussion}

The present results indicates that in presence of diabetes mellitus, the preserved endothelial function in prehypertensive premenopausal women was attenuated, which may be related to impaired number and function of circulating EPCs. This alteration in circulating EPCs may be due to decreased NO production, and the abnormal phosphorylation of Tie2/Akt/eNOS signaling pathway may be the underlying mechanism. Therefore, this study firstly demonstrates the unfavorable effects of diabetes mellitus on endothelial function and circulating EPCs in prehypertensive premenopausal women and its possible underlying mechanism.

Diabetes mellitus is a major risk factor for the development of cardiovascular disease and is associated with a high cardiovascular morbidity and mortality $[17,18]$. It is generally accepted that the number and function activity of circulating EPCs is impaired in diabetes patients [23-25], supporting the role of suppressed endothelial repair capacity in pathogenesis of diabetes-related vascular abnormalities. Our previous studies show that in prehypertension premenopausal women the number and activity of circulating EPCs were preserved [31], indicating that EPC-mediated vascular protection in prehypertension premenopausal women may due to increased endothelial repair capacity. However, the effect of diabetes on number and activity of circulating EPCs in prehypertension premenopausal women is unclear. In this investigation, we found that in presence of diabetes mellitus, both the number and functional activity of circulating EPCs is impaired in prehypertensive premenopausal women. FMD is regarded as a reliable and reproducible technique for assessment of endothelial dysfunction in cardiovascular disease [44-46]. Our results also revealed that FMD was reduced in prehypertensive premenopausal women in presence of diabetes mellitus and there is a significant correlation between the number or function activity of circulating EPCs and FMD, indicating that the attenuated endothelial repair capacity may lead to endothelial dysfunction in prehypertensive premenopausal women with diabetes mellitus.

NO、VEGF and GM-CSF are the pivotal factors to regulate the number and function of circulating EPCs [32-35]. Previous studies demonstrated that diabetes mellitus impairs eNOS activity, resulting in decreased NO bioavailability [47]. Accordingly, we assumed that the effect of diabetes mellitus on number and activity of circulating EPCs in prehypertension premenopausal women might be associated with NO、 VEGF and GMCSF. In result, we found that compared with normotensive premenopausal women, the plasma NO level or NO secretion by EPCs was restored in prehypertension premenopausal women, but reduced in prehypertensive premenopausal women with diabetes mellitus. The present results indicates that diabetes-related decreased number and activity of circulating EPCs in prehypertension premenopausal women may be related to the reduced NO production. However, no difference in VEGF 


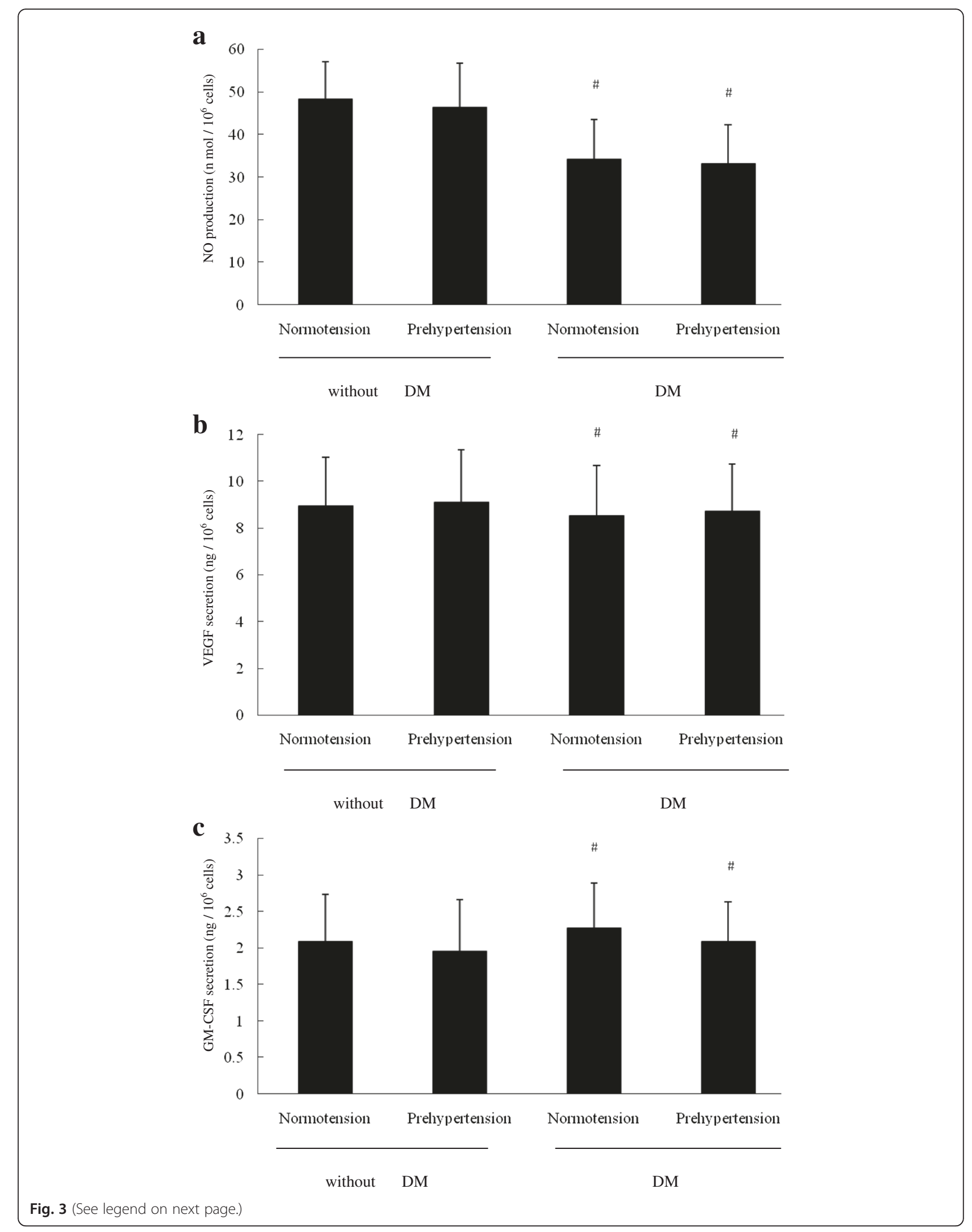


(See figure on previous page.)

Fig. 3 The NO、VEGF and GM-CSF secretion by EPCS in the four groups. a The NO secretion by EPCs was the same in normotensive premenopausal women without diabetes mellitus as that in prehypertensive premenopausal women without diabetes mellitus, but higher than that in normotensive or prehypertensive women with diabetes mellitus. There was no difference in VEGF $\mathbf{b}$ or GM-CSF $\mathbf{c}$ secretion by EPCs among the four groups. Data are given as mean $\pm \mathrm{SD}$ ( ${ }^{*}$ vs normotension; " vs without $\mathrm{DM}, n=20$ for each group)

or GM-CSF in plasma or secretion by cultured EPCs was found among the three groups, suggesting that the alteration of endothelial repair capacity in prehypertensive premenopausal women with diabetes mellitus may be independent of the changes in plasma VEGF or GMCSF level or secretion by cultured EPCs. In addition, we also found that there was a positive correlation between the plasma NO level or NO secretion by EPCs and FMD, further supporting that both reduced systemic NO production and endogenous NO biosynthase by circulating EPCs may contribute to endothelial dysfunction in prehypertensive premenopausal women with diabetes mellitus.

Tie2/Akt/eNOS pathway plays an important role in regulating the number and function of circulating EPCs and subsequently accelerating endothelial repair capacity for vascular injury [48-51]. In this investigation, we found that when compared with normotensive premenopausal women, the phosphorylation of tie2, Akt, and eNOS of circulating EPCs were preserved in prehypertensive premenopausal women without diabetes, but reduced in prehypertensive premenopausal women with diabetes mellitus. However, the expression of tie2, Akt and eNOS of circulating EPCs showed no difference in the three groups. These results indicate that the decreased phosphorylation of tie2, Akt, and eNOS but not the alteration of expression of Tie2/Akt/eNOS pathway contributes to reduced NO secretion by circulating EPCs in prehypertensive premenopausal women with diabetes mellitus. Interestingly, the phosphorylation of eNOS was slightly lower than the phosphorylation of tie2 and Akt of circulating EPCs in prehypertensive premenopausal women with diabetes mellitus, implying that other mechanism may be involved in abnormal activity of eNOS of circulating EPCs. Previous study reported that in circulating EPCs in presence of type 2 diabetes, GTPCH I deactivation leads to BH4 efficiency and subsequent eNOS uncoupling [52]. Thus, we inferred that GTPCH I deactivation may be another mechanism underlying the decreased phosphorylation of eNOS of circulating EPCs in prehypertensive premenopausal women with diabetes mellitus.

The present study has some implications as follows. First, different from prehypertensive premenopausal women without diabetes mellitus, the endothelial function together with number or activity of circulating EPCs in prehypertensive premenopausal women with diabetes mellitus were impaired, indicating that the intervention to improve endothelial function and vascular repair capacity may be necessary for prehypertensive

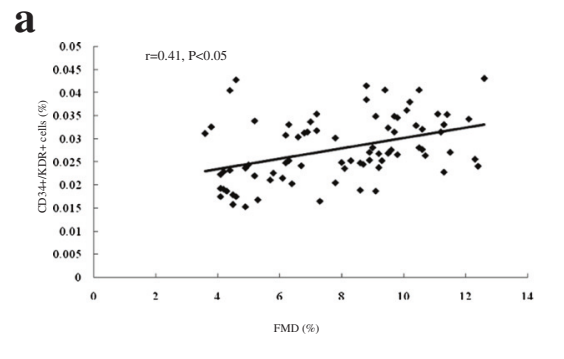

b

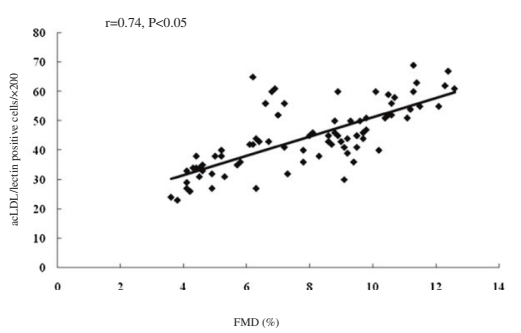

c

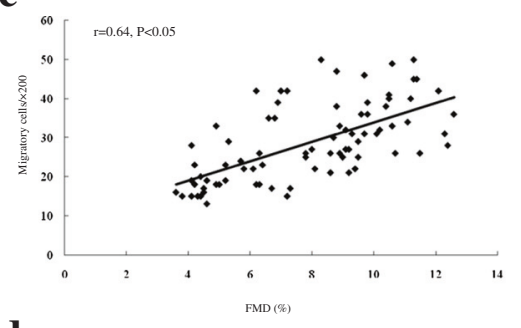

d

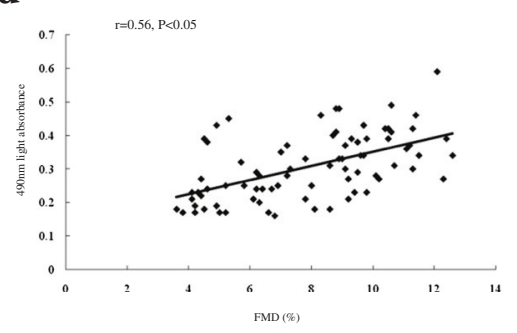

$\mathbf{e}$

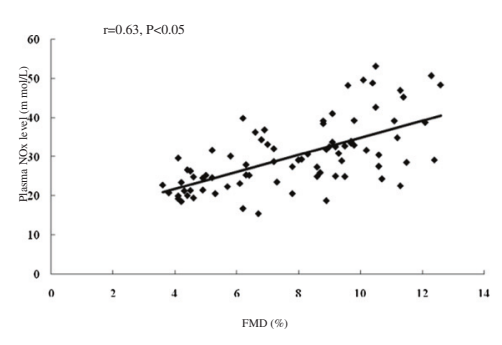

f

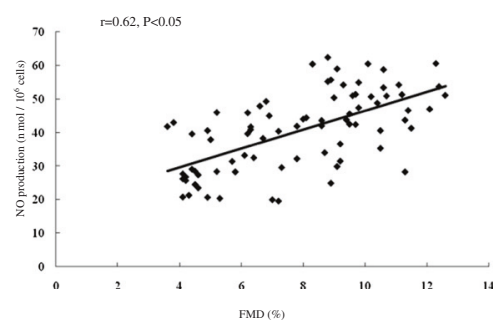

Fig. 4 The correlation between circulating EPCs or NO level and FMD. a and $\mathbf{d}$ showed that the correlation between the number or activity of circulating EPCs and FMD. The number of circulating EPCs evaluated by FACS $\mathbf{a}$ or by cell culture $\mathbf{b}$ strongly correlated with the FMD. There was a correlation between the EPC proliferatory $\mathbf{c}$ or migratory $\mathbf{d}$ and FMD. e and $\mathbf{f}$ showed that the correlation between the plasma NO level and NO secretion by EPCs and FMD. There was a correlation between the plasma NO level e or NO secretion by EPCs $\mathbf{f}$ and FMD 


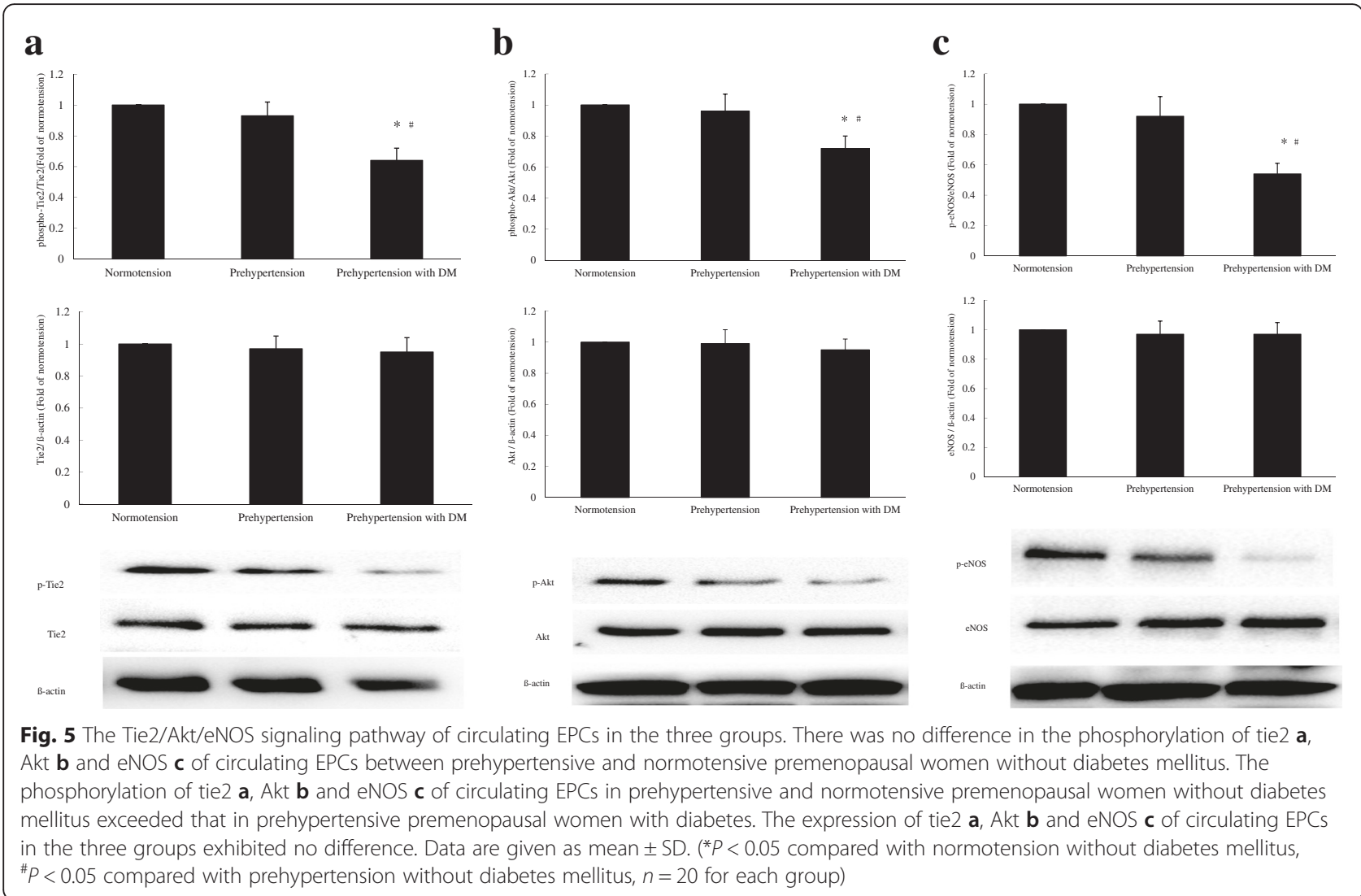

premenopausal women with diabetes mellitus. Second, our results show that diabetes mellitus impaired the number or function of circulating EPCs and subsequently reduced $\mathrm{NO}$ production in prehypertensive premenopausal women, which is at least in part mediated by tie2/Akt/eNOS signaling pathway. The date reported here proved that in presence of prehypertension with diabetes mellitus, the tie2/Akt/eNOS signaling pathway in circulating EPCs may be useful for therapeutic approach of endothelial repair capacity.

\section{Conclusions}

The present study for the first time demonstrates the unfavorable effects of diabetes on number and activity of circulating EPCs and endothelial function in prehypertensive premenopausal women, which is associated with decreased NO production and abnormal phosphorylation of Tie2/Akt/eNOS signaling pathway. The attenuated endogenous endothelial repair capacity may be the important mechanism underlying vascular injury in prehypertensive premenopausal women with diabetes. Our findings provide new insight into vascular protection in patients of prehypertensive premenopausal women with diabetes mellitus, suggesting that Tie2/Akt/eNOS signaling pathway may be a potential target for enhancing endogenous endothelial repair capacity.

\section{Abbreviations}

EPCs: Endothelial progenitor cells; DM: Diabetes mellitus; FMD: Flowmediated dilatation; NO: Nitric oxide; GM-CSF: Granulocyte macrophage colony-stimulating factor; VEGF: Vascular endothelial growth factors; Tie-2: Tyrosine kinase with immunoglobul in and epidermal growth factor homology domain-2; Akt: Protein kinase B; eNOS: Endothelial nitric oxide synthase; GMD: Glyceryltrinitrate-mediated dilation; MTT: 3-(4,5-Dimethylthiazol-2-yl)-2,5-Diphenyltetrazolium bromide; SD: Standard deviation; ANOVA: Analysis of variance; FACS: Fluorescence-activated cell sorting; NOx: Nitrate plus nitrite; GTPCH: Guanosine triphosphate cyclohydrolase; BH4: Tetrahydrobiopterin.

\section{Competing interests}

The authors declare that they have no competing interests.

\section{Authors' contributions}

$\mathrm{HZ}$ : designed and performed experiments, analyzed data, and wrote the manuscript. YJ: performed experiments and analyzed data; $\mathrm{HT}$ : performed experiments; ZR: performed experiments; GZ: designed research, interpretation and modification; ZY: designed research, analyzed data, and wrote the manuscript. All authors have read and approved the manuscript.

\section{Acknowledgments}

This study was financially supported by the grants from National Natural Scientific Foundation of China (31270992, 30800215 and 81100089), the project of Zhu Jiang Science and Technology new star of Guangzhou City (2013 J2200019), Guangdong Natural Science Foundation (No:

2014A030313086), the project of Guangdong Province Science and technology plan (2013B021800275), and the Fundamental Research Funds for the Central Universities in Sun Yat-Sen University (13ykpy24).

\section{Author details}

${ }^{1}$ Center for Reproductive Medicine, The Sixth Affiliated Hospital, Sun Yat-sen University, Guangzhou 510080, People's Republic of China. ${ }^{2}$ Department of 
Cardiovascular Medicine, The Second Affiliated Hospital of University of South China, Hengyang, Hunan 421001, China. ${ }^{3}$ Cancer Center, Sun Yat-sen University, Guangzhou 510080, People's Republic of China. ${ }^{4}$ Department of Hypertension \& Vascular Disease, The First Affiliated Hospital, Sun Yat-Sen University, Guangzhou 510080, People's Republic of China.

Received: 28 August 2015 Accepted: 25 February 2016

Published online: 02 March 2016

\section{References}

1. Lawes C, Hoorn S, Law M, Elliot P, MacMahon S, Rodgers A. Blood pressure and the global burden of disease 2000. Part II: estimates of attributable burden. J Hypertens. 2006;24:423-30.

2. Urbina EM, Khoury PR, McCoy C, Daniels SR, Kimball TR, Dolan LM. Cardiac and vascular consequences of pre-hypertension in youth. J Clin Hypertens (Greenwich). 2011;13:332-42.

3. Vasan RS, Larson MG, Leip EP, Evans JC, O'Donnell CJ, Kannel WB, et al. Impact of high-normal blood pressure on the risk of cardiovascular disease. N Engl J Med. 2001;345:1291-7.

4. Hsia J, Margolis KL, Eaton CB, Wenger NK, Allison M, Wu L, et al. Prehypertension and cardiovascular disease risk in the Women's Health Initiative. Circulation. 2007;115:855-60.

5. Weil BR, Westby CM, Greiner JJ, Stauffer BL, DeSouza CA. Elevated endothelin-1 vasoconstrictor tone in prehypertensive adults. Can J Cardiol. 2012;28:347-53.

6. Huang Y, Su L, Cai X, Mai W, Wang S, Hu Y, et al. Association of all-cause and cardiovascular mortality with prehypertension: a meta-analysis. Am Heart J. 2014;167:160-8.

7. Kissel CK, Anderson TJ. Role of endothelin-1 and endothelial dysfunction in prehypertension. Can J Cardiol. 2012;28:251-3.

8. Heitzer T, Schlinzig T, Krohn K, Meinertz T, Munzel T. Endothelial dysfunction, oxidative stress, and risk of cardiovascular events in patients with coronary artery disease. Circulation. 2001;104:2673-8.

9. Anderson TJ, Charbonneau F, Title LM, Buithieu J, Rose MS, Conradson H, et al. Microvascular function predicts cardiovascular events in primary prevention: long-term results from the Firefighters and Their Endothelium (FATE) study. Circulation. 2011;123:163-9.

10. Mehta JL, Szwedo J. Circulating endothelial progenitor cells, microparticles and vascular disease. J Hypertens. 2010;28(8):1611-3.

11. Dubsky M, Jirkovska A, Bem R, Fejfarova V, Pagacova L, Sixta B, et al. Both autologous bone marrow mononuclear cell and peripheral blood progenitor cell therapies similarly improve ischaemia in patients with diabetic foot in comparison with control treatment. Diabetes Metab Res Rev. 2013;29(5):369-76.

12. Du F, Zhou J, Gong R, et al. Endothelial progenitor cells in atherosclerosis. Front Biosci (Landmark Ed). 2012;17:2327-49.

13. Fadini GP, Losordo D, Dimmeler S, et al. Critical reevaluation of endothelia progenitor cell phenotypes for therapeutic and diagnostic use. Circ Res. 2012;110(4):624-37.

14. Giannotti G, Doerries C, Mocharla PS, Mueller MF, Bahlmann FH, Horvàth T, et al. Impaired endothelial repair capacity of early endothelial progenitor cells in prehypertension: relation to endothelial dysfunction. Hypertension. 2010;55:1389-97

15. Yang Z, Chen L, Su C, Xia WH, Wang Y, Wang JM, et al. Impaired endothelial progenitor cell activity is associated with reduced arterial elasticity in patients with essential hypertension. Clin Exp Hypertens. 2010;32:444-52

16. Lee PS, Poh KK. Endothelial progenitor cells in cardiovascular diseases. World J Stem Cells. 2014:6:355-66.

17. Fox CS. Cardiovascular disease risk factors, type 2 diabetes mellitus, and the Framingham Heart Study. Trends Cardiovasc Med. 2010;20:90-5.

18. Blonde L, Pencek R, MacConell L. Association among weight change, glycemic control, and markers of cardiovascular risk with exenatide once weekly: a pooled analysis of patients with type 2 diabetes. Cardiovasc Diabetol. 2015;14:12

19. Avogaro A, de Kreutzenberg SV, Fadini G. Endothelial dysfunction: causes and consequences in patients with diabetes mellitus. Diabetes Res Clin Pract. 2008:82(12):94-101

20. Waltenberger J. Impaired collateral vessel development in diabetes: potential cellular mechanisms and therapeutic implications. Cardiovasc Res. 2001;49:554-60
21. Sheetz MJ, King GL. Molecular understanding of hyper-glycemia's adverse effects for diabetic complications. JAMA. 2002;288:2579-88.

22. Tousoulis D, Kampoli AM, Stefanadis C. Diabetes mellitus and vascular endothelia dysfunction: current perspectives. Curr Vasc Pharmacol. 2012;10:19-32.

23. Liu Z-J, Velasquez OC. Hyperoxia, endothelial progenitor cell mobilization, and diabetic wound healing. Antioxid Redox Signal. 2008;10:1869-82.

24. Chen MC, Sheu JJ, Wang PW, et al. Complications impaired endothelial progenitor cell function in type 2 diabetic patients with or without critical leg ischaemia: implication for impaired neovascularization in diabetes. Diabetic Med. 2009;26:134-41.

25. Yiu KH, Tse HF. Specific role of impaired glucose metabolism and diabetes mellitus in endothelial progenitor cell characteristics and function. Arterioscler Thromb Vasc Biol. 2014;34:1136-43.

26. Deanfield JE, Halcox JP, Rabelink TJ. Endothelial function and dysfunction. Circulation. 2007:115:1285-95.

27. Lekakis J, Abraham P, Balbarini A, Blann A, Boulanger CM, Cockcroft J, et al. Methods for evaluating endothelial function:a position statement from the European Society of Cardiology Working Group on Peripheral Circulation. Eur J Cardiovasc Prev Rehabil. 2011;18:775-89.

28. Gavin KM, Seals DR, Silver AE, Moreau KL. Vascular endothelial estrogen receptor $a$ is modulated by estrogen status and related to endothelial function and endothelial nitric oxide synthase in healthy women. J Clin Endocrinol Metab. 2009:94:3513-20.

29. Moreau KL, Hildreth KL, Meditz AL, Deane KD, Kohrt WM. Endothelial function is impaired across the stages of the menopause transition in healthy women. J Clin Endocrinol Metab. 2012;97:4692-00

30. Denton KM, Hilliard LM, Tare M. Sex-related differences in hypertension: seek and ye shall find. Hypertension. 2013;62:674-7.

31. Zhen Y, Xiao S, Ren Z, Shen HW, Su H, Tang YB, et al. Increased Endothelial Progenitor Cells and Nitric Oxide in Young Prehypertensive Women. J Clin Hypertens (Greenwich). 2015;17(4):298-05.

32. Yang Z, Wang JM, Chen L, Luo CF, Tang AL, Tao J. Acute exercise-induced nitric oxide production contributes to upregulation of circulating endothelial progenitor cells in healthy subjects. J Hum Hypertens. 2007;21:452-60

33. Bonafe F, Guarnieri C, Muscari C. Nitric oxide regulates multiple functions and fate of adult progenitor and stem cells. J Physiol Biochem. 2015;71(1):141-53.

34. Xue J, Du G, Shi J, Li Y, Yasutake M, Liu L, et al. Combined treatment with erythropoietin and granulocyte colony-stimulatingfactor enhances neovascularization and improve scardiac function after myocardial infarction. Chin Med J. 2014;127(9):1677-83.

35. Shurygin MG, Shurygina IA, Dremina NN, Kanya OV. Endogenous Progenitors as the Source of Cell Material for Ischemic Damage Repair in Experimental Myocardial Infarction under Conditions of Changed Concentration of Vascular Endothelial Growth Factor. Bull Exp Biol Med. 2015:158(4):528-31.

36. Sorrentino SA, Bahlmann FH, Besler C, Muller M, Schulz S, Kirchhoff N, et al. Oxidant stress impairs in vivo reendothelialization capacity of endothelial progenitor cells from patients with type 2 diabetes mellitus: restoration by the peroxisome proliferator-activated receptor agonist rosiglitazone. Circulation. 2007;116:163-73

37. Jones N, lliin K, Dumont DJ, Alitalo K. Tie receptors:new modulators of angiogenic and lymphangiogenic responses. Nat Rev Mol Cell Biol. 2001:2(4):257-67.

38. Brindle NP, Saharinen P, Alitalo K. Signaling and function of angiopoietin-1 in vascular protection. Circ Res. 2006;98(8):1014-23.

39. Chong AY, Caine GJ, Freestone B, Blann AD, Lip GY. Plasma angiopoietin-1, angiopoietin-2, and angiopoietin receptor tie-2 levels in congestive heart failure. J Am Coll Cardiol. 2004:43(3):423-8.

40. Yang Z, Xia WH, Zhang YY, Xu SY, Liu X, Zhang XY, et al. Shear stressinduced activation of Tie2-dependent signaling pathway enhances in vivo reendothelialization capacity of human endothelial progenitor cells. J Mol Cell Cardiol. 2012:52:1155-63.

41. James PA, Oparil S, Carter BL, Cushman WC, Dennison-Himmelfarb C, Handler J, et al. 2014 evidence-based guideline for the management of high blood pressure in adults: report from the panel members appointed to the Eighth Joint National Committee (JNC 8). JAMA. 2014:311:507-20.

42. The Expert Committee on the Diagnosis and Classification of Diabetes Mellitus. Report of the Expert Committee on the Diagnosis and Classification of Diabetes Mellitus. Diabetes Care. 1997;20:1183-97. 
43. Yang Z, Xia WH, Su C, Wu F, Zhang YY, Xu SY, et al. Regular exerciseinduced upregulation of circulating endothelial progenitor cells attenuated age-related decline in arterial elasticity in healthy men. Int J Cardiol. 2013:165:247-54.

44. Corretti MC, Anderson TJ, Benjamin EJ, Celermajer D, Charbonneau F, Creager MA, et al. Guidelines for the ultrasound assessment of endothelialdependent flowmediated vasodilation of the brachial artery: a report of the International Brachial Artery Reactivity Task Force. J Am Coll Cardiol. 2002;39:257-65.

45. Sibal L, Aldibbiat A, Agarwal SC, Mitchell G, Oates C, Razvi S, et al. Circulating endothelial progenitor cells, endothelial function, carotid intima-media thickness and circulating markers of endothelial dysfunction in people with type 1 diabetes without macrovascular disease or microalbuminuria. Diabetologia. 2009;52:1464-73.

46. Hill JM, Zalos G, Halcox JP, Schenke WH, Waclawiw MA, Quyyumi AA, et al. Circulating Endothelial Progenitor Cells, Vascular Function, and Cardiovascular Risk. N Engl J Med. 2003;348(7):593-00.

47. Avogaro A, Toffolo G, Kiwanuka E, de Kreutzenberg SV, Tessari P, Cobelli C. L-Arginine-nitric oxide kinetics in normal and type 2 diabetic subjects: a stable-labelled $15 \mathrm{~N}$ arginine approach. Diabetes. 2003;52:795-02.

48. Shyu K-G. Enhancement of new vessel formation by Angiopoieti n-2/Tie2 signaling in endothelial progenitor cells: a new hope for future therapy? Cardiovasc Res. 2006;72(3):359-60

49. Hildbrand P, Cirulli V, Prinsen RC, Smith KA, Torbett BE, Salomon DR, et al. The role of angiopoietins in the development of endothelial cells from cord blood CD34 + progenitors. Blood. 2004:104(7):2010-9.

50. Morello F, Perino A, Hirsch E. Phosphoinositide 3-kinase signalling in the vascular system. Cardiovasc Res. 2009;82:261-71.

51. Fulton D, Gratton JP, McCabe TJ, Fontana J, Fujio Y, Walsh K, et al. Regulation of endothelium-derived nitric oxide production by the protein kinase Akt. Nature. 1999;399:597-01.

52. Thum T, Fraccarollo D, Schultheiss M, Froese S, Galuppo P, Widder JD, et al. Endothelial nitric oxide synthase uncoupling impairs endothelial progenitor cell mobilization and function in diabetes. Diabetes. 2007;56:666-74.

\section{Submit your next manuscript to BioMed Central and we will help you at every step:}

- We accept pre-submission inquiries

- Our selector tool helps you to find the most relevant journal

- We provide round the clock customer support

- Convenient online submission

- Thorough peer review

- Inclusion in PubMed and all major indexing services

- Maximum visibility for your research

Submit your manuscript at www biomedcentral.com/submit

) Biomed Central 